Article

\title{
Simulation of a Novel Configuration for Luminescent Solar Concentrator Photovoltaic Devices Using Bifacial Silicon Solar Cells
}

\author{
Mohammadreza Aghaei ${ }^{1, *}\left(\mathbb{C}\right.$, Marcello Nitti $^{1}$, Ned J. Ekins-Daukes ${ }^{2}$ and \\ Angèle H.M.E. Reinders 1,3,* \\ 1 Energy Technology Group, Department of Mechanical Engineering, Eindhoven University of Technology, \\ 5612 AE Eindhoven, The Netherlands; m.nitti@student.tue.nl \\ 2 School of Photovoltaic \& Renewable Energy Engineering, University of New South Wales (UNSW), \\ Sydney 2052, Australia; nekins@unsw.edu.au \\ 3 Department of Design, Production and Management, Faculty of Engineering Technology, \\ University of Twente, 7522 NB Enschede, The Netherlands \\ * Correspondence: m.aghaei@tue.nl (M.A.); a.h.m.e.reinders@tue.nl (A.H.M.E.R.)
}

Received: 27 November 2019; Accepted: 22 January 2020; Published: 28 January 2020

\begin{abstract}
In this study, a novel configuration for luminescent solar concentrator photovoltaic (LSC PV) devices is presented, with vertically placed bifacial PV solar cells made of mono-crystalline silicon (mono c-Si). This LSC PV device comprises multiple rectangular cuboid lightguides, made of poly (methyl methacrylate) (PMMA), containing Lumogen dyes, in particular, either Lumogen red 305 or orange 240. The bifacial solar cells are located in between these lightguide cubes and can, therefore, receive irradiance at both of their surfaces. The main aim of this study is to theoretically determine the power conversion efficiency (PCE) of five differently configured LSC PV devices. For this purpose, Monte Carlo ray tracing simulations were executed to analyze the irradiance at receiving PV cell surfaces, as well as the optical performance of these LSC PV devices. Five different LSC PV devices, with different geometries and varying dye concentrations, were modeled. To maximize the device efficiency, the bifacial cells were also attached to the back side of the lightguides. The ray tracing simulations resulted in a maximum efficiency of $16.9 \%$ under standard test conditions (STC) for a $15 \times 15 \mathrm{~cm}^{2}$ LSC PV device, consisting of nine rectangular cuboid $5 \times 5 \times 1 \mathrm{~cm}^{3}$ PMMA lightguides with 5 ppm orange 240 dye, with 12 vertically positioned $5 \times 1 \mathrm{~cm}^{2}$ bifacial cells in between the lightguides and nine $5 \times 5 \mathrm{~cm}^{2} \mathrm{PV}$ cells attached to the back of the device. If the cells are not applied to the back of this LSC PV device configuration, the maximum PCE will be 2.9\% (under STC), where the LSC PV device consists of 25 cubical $1 \times 1 \times 1 \mathrm{~cm}^{3}$ PMMA lightguides with $110 \mathrm{ppm}$ red 305 dye and 40 vertically oriented bifacial PV cells of $1 \times 1 \mathrm{~cm}^{2}$ in between the lightguides. These results show the vast future potential for LSC PV technologies, with a higher performance and efficiency than the common threshold PCE for LSC PV devices of $10 \%$.
\end{abstract}

Keywords: luminescent solar concentrator photovoltaic (LSC PV); ray tracing; simulation; power conversion efficiency (PCE); bifacial solar cells

\section{Introduction}

The luminescent solar concentrator photovoltaic collector (LSC PV) shown in Figure 1 holds several attractive features over existing conventional PV modules that are usually dark in color and are of a fixed thin, flat and rectangular shape, and so cannot meet the design requirements for the proper integration of photovoltaic technologies in products and buildings-so-called building integrated PV (BIPV). On the other hand, LSCs support colorful surfaces, transparency and provide form freedom, 
offering many design opportunities to enhance the overall functionality and experience of PV power generation within consumer products, the built environment and transportation [1,2].

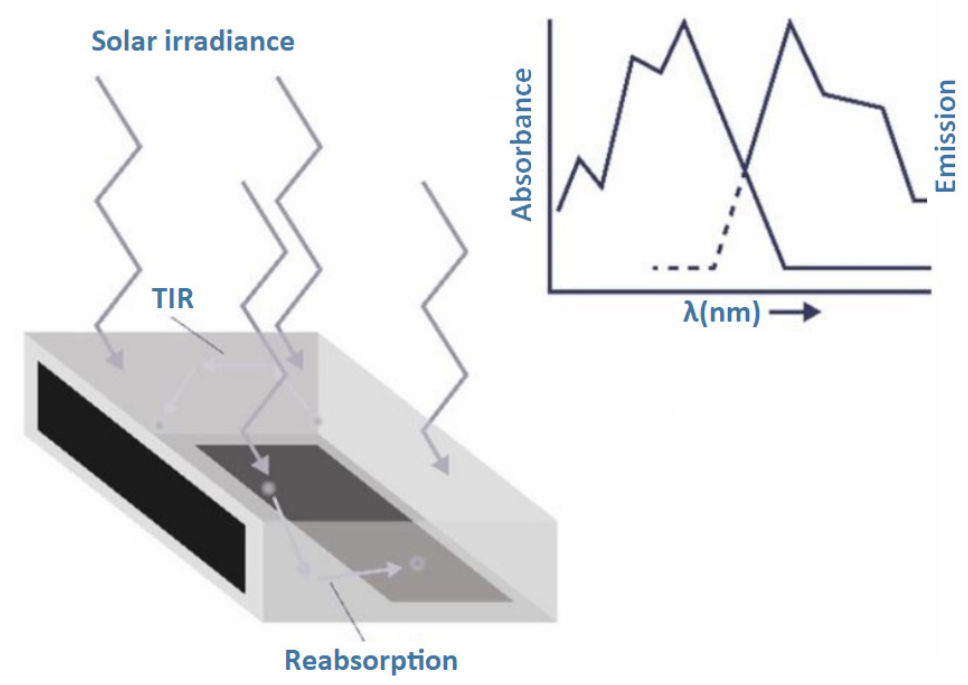

Figure 1. The design and working principle of a luminescent solar concentrator photovoltaic (LSC PV) element, with solar cells attached to the edges, showing the absorption spectrum (solid line) and the emission spectrum (dotted line) of a dye in an LSC.

The LSC is a technology [3,4] for harvesting solar energy that is comprised of a transparent element which serves to guide light to PV solar cells. These cells act as the receivers for the solar irradiance and generate electrical power-a typical configuration of this is shown in Figure 1. The LSC lightguide, which is usually made of polymer, glass or another transparent material, has a refractive index that is higher than air and contains luminescent pigments or luminophores, often molecular dyes. Sunlight, either direct or diffuse, is absorbed by dye molecules and, upon re-radiation, is guided by total internal reflection (TIR) to the photovoltaic solar cells at the periphery of the solar cell. Combining the concentration of irradiance and the transformation of the incoming spectrum in one solar device offers the potential for an efficient energy conversion process. Typically, an ideal LSC PV consists of a host material with a higher transparency, and a low scattering and attenuation coefficient, that is compatible with the dispersal of luminescent dyes [5,6]. Moreover, the emission spectra of the luminophores should be matched with the spectral response of the solar cells [7].

In the past, however, LSC PV technologies have only shown moderate power conversion efficiencies (PCE), in the range of $2 \%-7 \%$ [1]. To date, these technologies have not been considered a serious alternative to conventional PV technologies. However, they do have the potential for an improved performance, while providing a design freedom that is difficult to achieve with conventional photovoltaic modules. The aim of this work, therefore, is to further develop the LSC PV elements for the enhancement of the product applications of PV, leading to higher efficiencies beyond the $10 \%$ threshold for LSC PV technologies that is often claimed in the literature [8]. Hitherto, various monofacial solar cells have been studied for their attachment to LSCs [9]. However, bifacial solar cells absorb the direct and diffuse irradiance impinging on the front and rear side, which increases the output power when compared to monofacial solar cells. This increase in power can exceed that of a monofacial cell by $35 \%$ and $70 \%$ under sunny and cloudy conditions, respectively $[10,11]$. This is because the output power of the bifacial cells depends on the albedo of its surroundings and, in particular, on the albedo of the surface underneath the backside of such a solar cell [12].

At the beginning of 2019, a summer school was organized on the topic of "Exciton Solar + Design", with the aim of cross-fertilizing scientific research on the control of molecular excitons with the design potential of LSC PV applications. This summer school was composed of scientists, students and design 
professionals and involved formal lectures, design exercises and practical outdoor field testing of LSC PV devices. Several conceptual designs from the 15 participants were developed and presented during this summer school. They were partially evaluated by the ray tracing simulations in order to explore their optical performance. Figure 2 shows one of the results that emerged from this exercise, depicting a new design for an LSC PV device that contains bifacial solar cells. In this paper, we evaluate the optical performance and expected theoretical power conversion efficiency for this novel, design-driven solar collector. The details of the simulation that was conducted is presented in Section 2 and the results are discussed in Sections 3 and 4, which present the main findings of our study, with recommendations for further research.

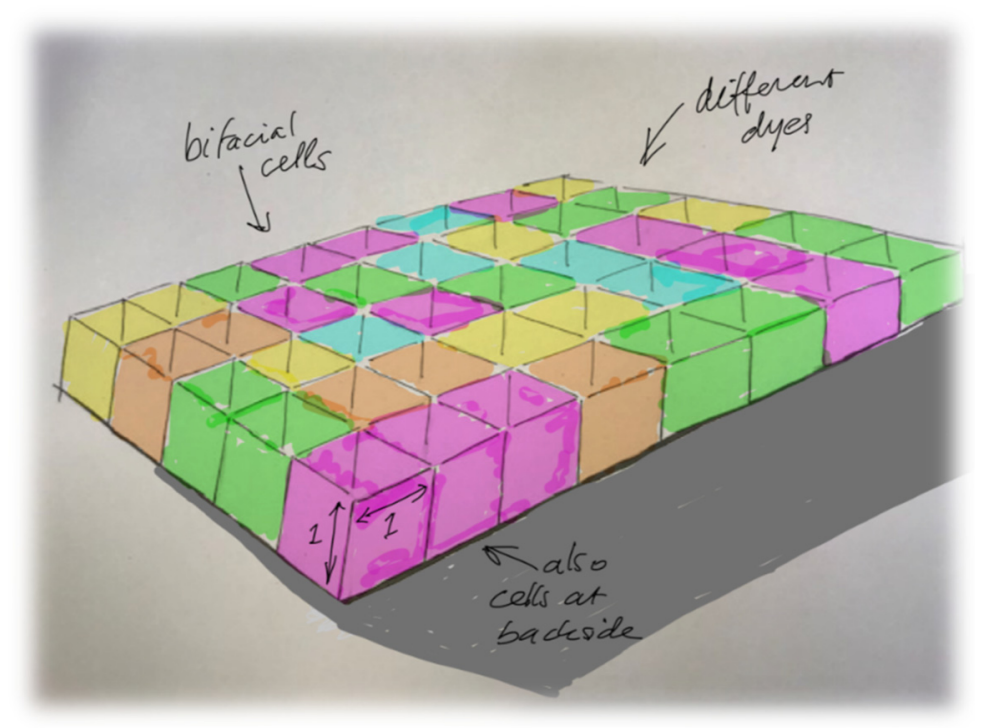

Figure 2. A sketch of a bifacial LSC PV mini-module for building-integrated PV (BIPV) applications by Ned Ekins-Daukes and Angèle Reinders, made during the Exciton Solar + Design Summer School at the University of New South Wales (UNSW), Sydney, 2019.

\section{Materials and Methods}

The ray tracing simulations were conducted to evaluate the performance of the novel design configuration for the LSC PV, using mono-crystalline silicon bifacial solar cells (mono c-Si) and several rectangular cuboid lightguides made of poly (methyl methacrylate) (PMMA). This approach follows prior studies that were based on Monte Carlo ray tracing methods which evaluated the geometrical effects and other features of LSC PV devices [13-16]. Here, a PMMA matrix acted as a lightguide and host for the organic dyes, namely Lumogen red 305 and orange 240. The LightTools software was used to perform the ray tracing simulations, in order to determine the irradiance received on the solar cell surface, as well as to analyze the optical performance and power conversion efficiency of these LSC PV devices.

\subsection{Design Configurations}

In this research, five different LSC PV devices were defined and simulated. The devices had different configurations in terms of their size, number of solar cells and their position on the lightguide, as shown in Table 1. Figure 3 depicts the geometry set up for one of the LSC PV devices, to show the modeling concepts that were applied to other devices as well. Of the many different combinations of dimensions, we restricted the analysis to only two larger dimensions with a different number of rectangular cuboid and bifacial cells, due to the similarity of the cases in terms of their configuration. 
Table 1. The configurations of the simulated LSC PV devices.

\begin{tabular}{|c|c|c|c|c|c|c|c|}
\hline Case & Configuration & $\begin{array}{l}\text { Number } \\
\text { of Cubes }\end{array}$ & $\begin{array}{c}\text { Cubes } \\
\text { Dimensions }\end{array}$ & $\begin{array}{c}\text { PV Cell } \\
\text { Dimensions-Cells } \\
\text { on Sides }\end{array}$ & $\begin{array}{c}\text { PV Cell } \\
\text { Dimensions-Cells } \\
\text { on Back }\end{array}$ & $\begin{array}{c}\text { Number } \\
\text { of Cells } \\
\text { on Sides }\end{array}$ & $\begin{array}{l}\text { Number } \\
\text { of Cells } \\
\text { on Back }\end{array}$ \\
\hline 1 & 5 unit cubes & 5 & $1 \times 1 \times 1 \mathrm{~cm}^{3}$ & $1 \times 1 \times 0.02 \mathrm{~cm}^{3}$ & $1 \times 1 \times 0.02 \mathrm{~cm}^{3}$ & 4 & 5 \\
\hline 2 & 3 by 3 unit cubes & 9 & $1 \times 1 \times 1 \mathrm{~cm}^{3}$ & $1 \times 1 \times 0.02 \mathrm{~cm}^{3}$ & $1 \times 1 \times 0.02 \mathrm{~cm}^{3}$ & 12 & 9 \\
\hline 3 & 5 by 5 unit cubes & 25 & $1 \times 1 \times 1 \mathrm{~cm}^{3}$ & $1 \times 1 \times 0.02 \mathrm{~cm}^{3}$ & $1 \times 1 \times 0.02 \mathrm{~cm}^{3}$ & 40 & 25 \\
\hline 4 & 5 rectangular cuboids & 5 & $5 \times 5 \times 1 \mathrm{~cm}^{3}$ & $5 \times 1 \times 0.02 \mathrm{~cm}^{3}$ & $5 \times 5 \times 0.02 \mathrm{~cm}^{3}$ & 4 & 5 \\
\hline 5 & $\begin{array}{c}3 \text { by } 3 \text { rectangular } \\
\text { cuboids }\end{array}$ & 9 & $5 \times 5 \times 1 \mathrm{~cm}^{3}$ & $5 \times 1 \times 0.02 \mathrm{~cm}^{3}$ & $5 \times 5 \times 0.02 \mathrm{~cm}^{3}$ & 12 & 9 \\
\hline
\end{tabular}

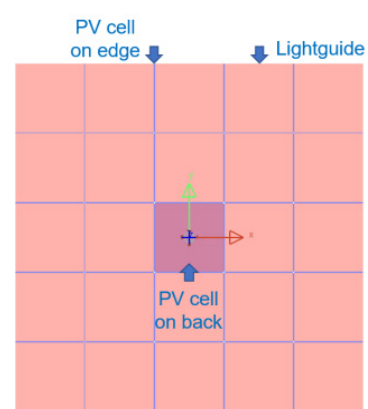

(a)

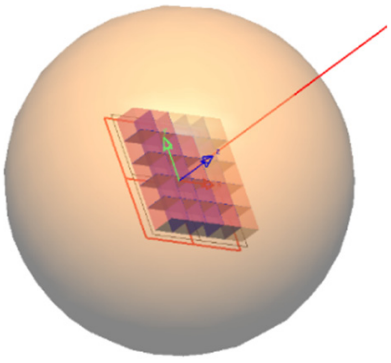

(b)

Figure 3. The geometry of the LSC PV device shown in Case 3 of Table 1: (a) top view of device; (b) the orange sphere shows the diffuse irradiance and the red line indicates the direction of the direct beam irradiance.

The devices were modeled in two ways, namely (1) where the LSCs had the solar cells attached between the neighboring lightguides, and (2) with the solar cells both attached between neighboring the lightguides and at the back of the LSC PV device. This concept can be extended to arrays with $\mathrm{n} \times \mathrm{m}$ units of LSC PV devices. The simulations do not cover scenarios with PV cells attached to the outer edge of the full LSC PV array of $n \times m$ units, because these outer-edge cells would form a barrier to the incoming irradiance.

\subsection{Simulation Setup}

In this research, the LSC PV devices were simulated in the ray tracing software LightTools. The mathematical technique that is implemented to trace light paths in an optical system is called "ray tracing". This method traces the light paths based on a number of factors related to the physical interaction of the photons with their surroundings, such as absorption, refraction, reflection, total internal reflection (TIR), emission and transmission. In an LSC PV device, the photons go through events that are both stochastic and probabilistic by nature. As such, Monte Carlo ray tracing has proven to be a very useful method to predict the performance of LSC PV devices and to calculate their optical efficiency (OE) [17]. In this study, the incident photons were traced from their entry into the LSC PV device, until they were absorbed, re-emitted and escaped from the devices, or were collected by the solar cells attached [18].

There are different types of software that can be used to conduct the ray tracing simulation of an LSC PV device. However, the software LightTools was chosen in this study due to its ability to handle complex geometries and to simulate the LSC PV devices under standard test conditions (STC: $1000 \mathrm{~W} / \mathrm{m}^{2}$, AM 1.5 spectrum and $25^{\circ} \mathrm{C}$ ). Furthermore, LightTools provides many robust design features and visualization tools to create a 3D model of the LSC PV device and to accurately evaluate its performance.

As mentioned before, the rectangular lightguides consisted of PMMA (as the host material) which was mixed with two luminescent dyes, namely Lumogen red 305 and Lumogen orange 240. These organic dyes have a high photoluminescence quantum yield (PLQY). Moreover, these organic dyes are 
inexpensive and have a simple mixing procedure with PMMA, in comparison with other luminescent materials. Lumogen red 305 and orange 240 are highly matched to the band gap of the silicon solar cells when compared to other dyes. Figure 4 depicts the absorption and emission spectra of Lumogen red 305 , orange 240 dyes, versus the quantum efficiency curve of a silicon solar cell.

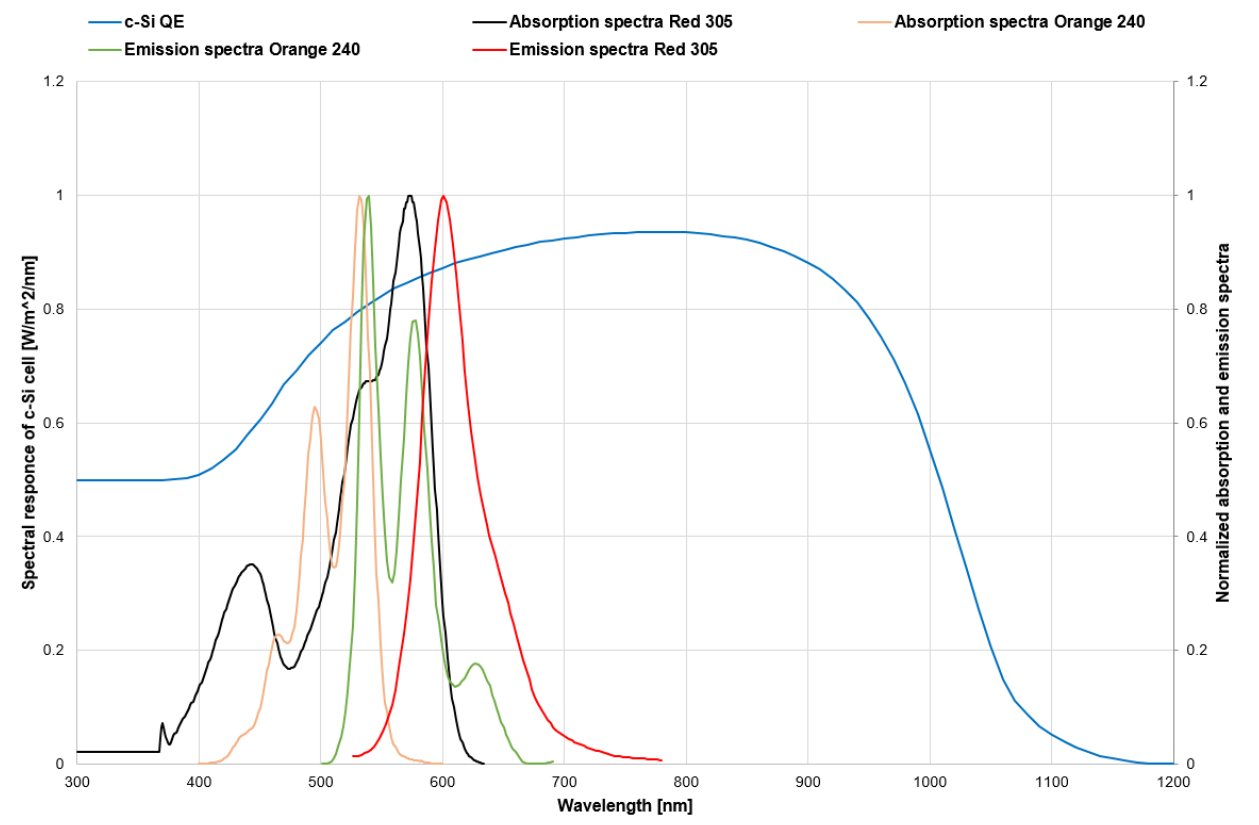

Figure 4. The quantum efficiency curve of a silicon solar cell versus the normalized absorption and emission spectra of the Lumogen red 305 and orange 240 dyes.

For each device, a 3D model was created of all of the physical components, which was imported into LightTools for the 3D ray tracing simulations-see Figure 5. In this 3D model, the material properties were defined as follows. PMMA was a standard material in LightTools, with a refractive index of 1.49 at $589 \mathrm{~nm}$. The dyes had absorption and emission curves, as shown in Figure 4 . The silicon solar cells were modeled as receiver planes with a refraction index of 3.4 at $550 \mathrm{~nm}$.

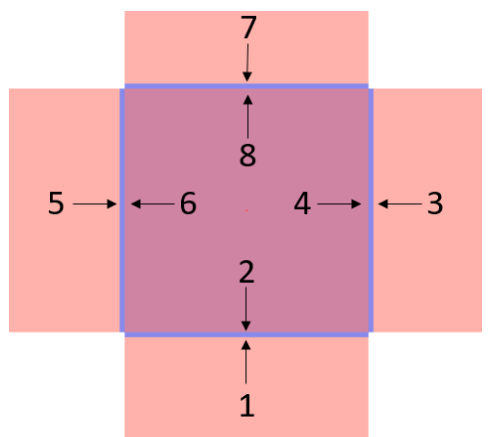

(a)

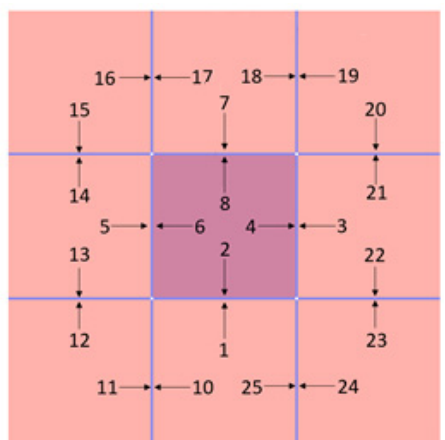

(b)

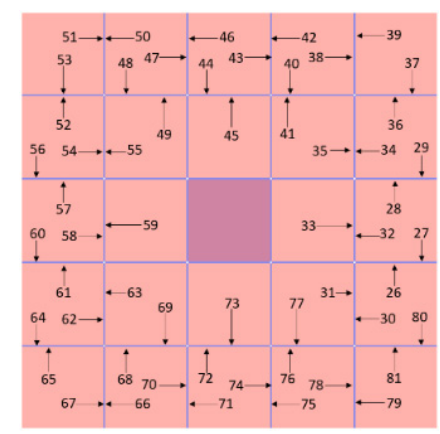

(c)

Figure 5. (a) The receiver positions in case 1 and 4; (b) the receiver positions in Case 2 and 5; (c) the receiver positions in Case 3.

In Figure 4, the red dye had two absorption peaks at 444 and $574 \mathrm{~nm}$ and also had a single emission peak at $601 \mathrm{~nm}$. The orange dye had two absorption peaks at 497 and $532 \mathrm{~nm}$ and also two emission peaks at 539 and at $581 \mathrm{~nm}$. The Stokes shift of the red and the orange dye was equal to 27 and $7 \mathrm{~nm}$, respectively. Therefore, the red dye showed a larger absorption band and a higher Stokes shift than the orange dye, which means that an LSC PV device with a red luminescent dye might be 
slightly more efficient. The STC efficiency of the mono c-Si bifacial solar cells, which were attached to the sides and the back of the lightguides, was set at $20 \%$. The ray tracing simulations were carried out under STC with 70\% direct and 30\% diffuse irradiance, respectively. The direct irradiance source was oriented as perpendicular toward each device in a long distance, while the diffuse irradiance source was positioned surrounding the whole device. The number of rays varied between 1 million and 5 million, which is sufficient for precise analysis. The dye concentration was increased from 5 to $110 \mathrm{ppm}$ where the device reached saturation point, meaning that a further increase in the dye concentration would have led to a decrease in the light passing through the device. The formula that was related to tuning the concentration is presented in Equation (1) [19]

$$
c=\frac{P P M}{M w}
$$

where $c\left[\mathrm{~mol} / \mathrm{m}^{3}\right]$ is the concentration, PPM represents the particle per million and $\mathrm{Mw}[\mathrm{g} / \mathrm{mol}]$ indicates the molecular weight of the substance. PPM was calculated through Equation (2) [19].

$$
1 P P M=1 \frac{m g}{L} \quad 1 L=0.001 m^{3}
$$

C was tuned to change the dye concentration for the Lumogen red 305 and orange 240. It has to be taken into account that the orange dye reached the saturation point at a lower concentration compared to the red dye because of two reasons, namely (1) molecular weight and (2) a different absorption coefficient. In addition, the molecular weight of the orange dye was lower than the red dye. This means that the orange dye had a higher concentration than the red dye at an equal ppm. Furthermore, the orange dye had double the absorption coefficient compared to the red dye. As a result, these effects caused an early saturation of the orange dye during the mixing procedure [20]. The efficiency of LSC PV devices was calculated through Equation (3)

$$
\eta_{L S C P V}=\frac{P_{P V}}{(G \times A)}
$$

where $P_{\mathrm{PV}}(\mathrm{W})$ is the output power of the solar cells, $\mathrm{G}$ is the irradiance $\left(1000 \mathrm{~W} / \mathrm{m}^{2}\right)$ and $\mathrm{A}$ is the aperture area $\left(\mathrm{cm}^{2}\right)$ of the lightguide.

\section{Results}

\subsection{Incident Irradiance on the Cells' Surfaces}

In the scenario with the highest share of direct irradiance (100\%), all of the cells on the sides received almost the same irradiance. However, the cells attached to the back received a higher solar irradiance where PMMA was mixed with the orange dye when compared to the red dye (see Figure 6). This is because the orange dye had a smaller absorption spectrum, and most parts of the solar spectrum passed through the lightguide with the orange dye rather than the red one. However, the orange dye, at a lower concentration, performed better compared to the red dye because the absorbance of the orange dye was higher. However, at higher concentrations, the red dye had a more effective performance, due to the orange dye absorbing and emitting the photons more at lower concentrations in comparison with the red dye. This effect led to a higher irradiance reception. In this scenario, the larger rectangular cuboids indicated a higher efficiency due to a better exposure of the PV cell at the backside of the LSC device to the irradiance. 


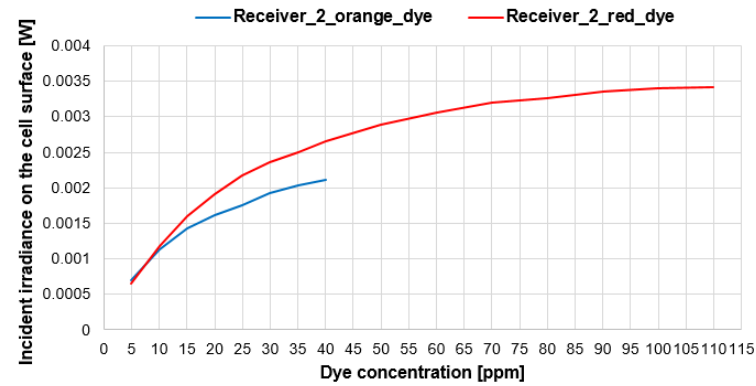

(a)

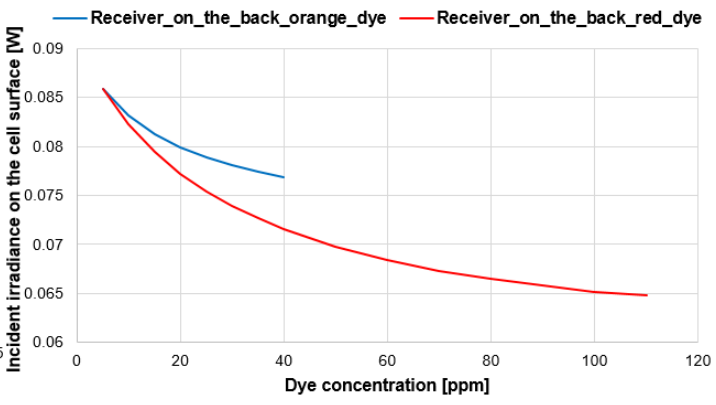

(b)

Figure 6. A comparison of the direct incident irradiance on the solar cells in LSC PV design Configuration 2-see Table 1-under exposure to standard test conditions (STC) irradiance (1000 W/m², 100\% direct) for the case of the orange and the red dyes: (a) the solar cell surface in between the lightguides; (b) the solar cell surface at the back.

Reducing the share of the direct irradiance caused a lower incident irradiance to be emitted on the solar cells which were placed at the edges of the devices. In this situation, the incident irradiance was increased with the increase in the dye concentration for the cells that faced the inner side of the lightguide. However, the presence of the diffuse light led to the incident irradiance being perpendicular to the surface of the cells at the edges. In such a situation, increasing the dye concentration decreases the irradiance that passes through the lightguide, hence the incident irradiance for the cells attached on the edges was almost similar to the cells placed on the back of the lightguide-see Figure 7.

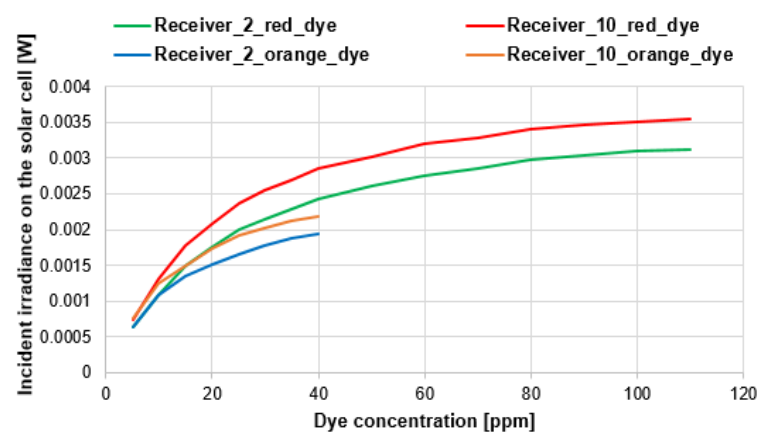

(a)

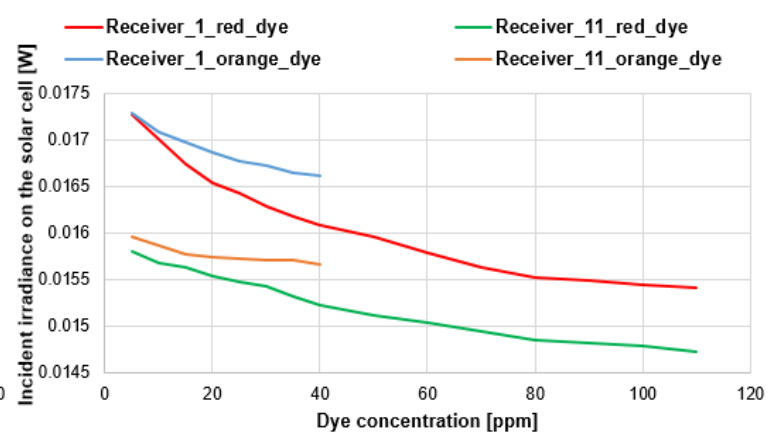

(b)

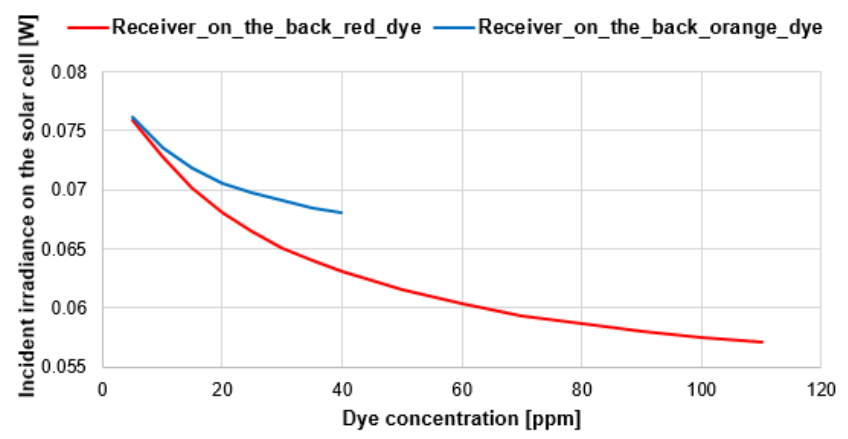

(c)

Figure 7. A comparison of the diffuse incident irradiance on the solar cells in LSC PV design Configuration 2-see Table 1-under exposure to STC irradiance $\left(1000 \mathrm{~W} / \mathrm{m}^{2}, 50 \%\right.$ direct and $50 \%$ diffuse) for the case of the orange and the red dyes: (a) the solar cells surface in between the lightguides, inner sides; (b) the solar cell surface in between the lightguides, outer sides; (c) the solar cell surface at the back. 


\subsection{Power Conversion Efficiency}

Figure 8 shows the efficiency of the LSC PV devices as a function of the dye concentration for the optimal cases with a higher performance. As illustrated in Figure 8, the efficiency of the device without the bifacial cells on the back was increased, whereas the efficiency of the device with the bifacial cells on the edge and back was decreased. The increase in the dye concentration led to an increase in the incident irradiance for the solar cells attached on the sides, and also a decrease in the incident irradiance for the bifacial cells placed on the back. Table 2 summarizes the efficiencies of the LSC PV devices with optimum configuration and performance. These results were obtained based on the minimum and maximum range of the dye concentration (i.e., Lumogen red 305 and orange 240) and also the position of the bifacial solar cells attached on the lightguide.



(a)

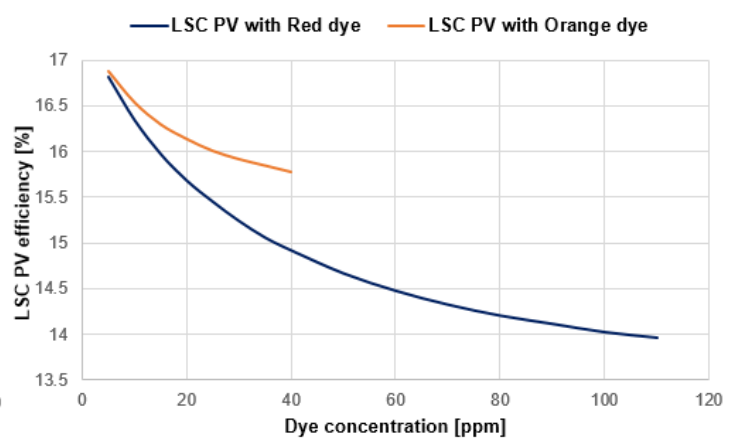

(b)

Figure 8. The efficiency of the LSC PV devices as a function of the dye concentration: (a) the device with the cells on the edges (case 3); (b) the device with the cells on the back and on the edges (case 5).

Table 2. The LSC PV efficiency of the optimal cases.

\begin{tabular}{ccccccccc}
\hline & \multicolumn{4}{c}{ Orange Dye } & \multicolumn{3}{c}{ Red Dye } \\
\hline & \multicolumn{3}{c}{ Full Device } & \multicolumn{2}{c}{$\begin{array}{c}\text { Device with Only } \\
\text { Side Cells }\end{array}$} & Full Device & \multicolumn{2}{c}{$\begin{array}{c}\text { Device with Only } \\
\text { Side Cells }\end{array}$} \\
\hline Case & Min & Max & Min & Max & Min & Max & Min & Max \\
3 & 14.53 & 15.45 & 1.75 & 2.32 & 13.12 & 15.44 & 1.71 & 2.9 \\
5 & 12.97 & $\mathbf{1 6 . 9}$ & 0.89 & 2.46 & 11.57 & 16.81 & 0.84 & 2.72 \\
\hline
\end{tabular}

According to the results, the highest power conversion efficiency was $16.9 \%$ under STC, with 70\% direct and 30\% diffuse irradiance obtained for the LSC PV device with the bifacial cells on the back and sides with the three by three rectangular cuboids $\left(5 \times 5 \times 1 \mathrm{~cm}^{3}\right)$ at $5 \mathrm{ppm}$ orange 240 dye concentration. The highest efficiency, considering only the bifacial cells on the side, was up to $2.9 \%$ under STC for the LSC PV device with the five by five unit cubes $\left(1 \times 1 \times 1 \mathrm{~cm}^{3}\right)$ and the red 305 dye at $110 \mathrm{ppm}$.

\section{Conclusions}

In the past, many efforts were devoted to developing different configurations of LSC PV to increase the OE and PCE. In all cases, the monofacial solar cells from various technologies were attached to the LSC devices in order to convert the light into electricity.

In the current study, a novel configuration for LSC PV was presented in various geometries and dye concentrations, with vertically placed bifacial PV solar cells made of mono c-Si. The main aim of this study was to theoretically determine the PCE of five differently configured LSC PV devices. For this purpose, the LSC PV devices with different geometries were modeled and simulated using a ray tracing software called LightTools. The lightguide was made of multiple rectangular cuboids which were mixed with organic dyes, namely Lumogen red 305 and orange 240. The emission spectra of these luminescent materials were matched to the spectral response and the quantum efficiency (QE) of 
the bifacial solar cells. In each device, the mono c-Si bifacial solar cells were placed in between the two neighboring lightguides. To maximize the LSC PV device efficiency, the bifacial cells were also attached at the back side of the lightguides.

This study has been able to demonstrate that an increase in dye concentration will lead to a lower efficiency in the devices with the bifacial cells on the back and the edges. This is because such increase in concentration results in a lower incident irradiance on the bifacial cells positioned on the back, and a higher incident irradiance on the bifacial cells placed on the sides. On the other hand, an increase in efficiency was shown when the bifacial cells were only on the edges of the collector.

The results of the ray tracing simulation have indicated that the maximum efficiency was equal to $16.9 \%$ (under STC) where the dimension of the LSC PV device was $15 \times 15 \mathrm{~cm}^{2}$, consisting of nine rectangular cuboid $5 \times 5 \times 1 \mathrm{~cm}^{3}$ PMMA lightguides, with Lumogen orange 240 (at $5 \mathrm{ppm}$ ), with 12 vertically positioned $5 \times 1 \mathrm{~cm}^{2}$ bifacial solar cells in between the lightguides and nine $5 \times 5 \mathrm{~cm}^{2} \mathrm{PV}$ cells attached to the back of the device. However, the maximum PCE of $2.9 \%$ under STC was obtained for an LSC PV device consisting of 25 cubical $1 \times 1 \times 1 \mathrm{~cm}^{3}$ PMMA lightguides, with 110 ppm red 305 dye and 40 vertically oriented bifacial PV cells of $1 \times 1 \mathrm{~cm}^{2}$ in between the lightguides.

The results have demonstrated that such a concept shows promise in the commercial production of LSC PV devices with visual appeal for a built environment, for example, in facades, PV-powered vehicles, and so on. However, in reality, there are many challenges in creating such LSC PV devices based on these simulation results-for example, the electrical interconnection of the numerous bifacial solar cells is likely to be complicated.

Author Contributions: Validation, visualization, writing and editing-M.A.; Investigation, simulation and visualization-M.N.; Conceptualization, invention and editing-N.J.E.-D.; Conceptualization, invention, investigation, writing, editing and supervision-A.H.M.E.R. All authors have read and agreed to the published version of the manuscript.

Funding: We would like to acknowledge the Department of Mechanical Engineering of Eindhoven University of Technology for funding this research line on LSC PV devices and, also, AHMER acknowledges the financial support from the ARC Centre of Excellence for Exciton Science during her visit to the University of New South Wales (UNSW) for the Exciton Solar + Design summer school.

Conflicts of Interest: The authors declare no conflict of interest.

\section{References}

1. Reinders, A.; Kishore, R.; Slooff, L.; Eggink, W. Luminescent solar concentrator photovoltaic designs. Jpn. J. Appl. Phys. 2018, 57, 08RD10. [CrossRef]

2. Reinders, A.; Diehl, J.C.; Brezet, H. The Power of Design: Product Innovation in Sustainable Energy Technologies; Wiley: Hoboken, NJ, USA, 2012.

3. Goetzberger, A. Fluorescent solar energy collectors: Operating conditions with diffuse light. Appl. Phys. 1978, 16, 399-404. [CrossRef]

4. Yablonovitch, E. Thermodyamics of the fluorescent planar concentrator. J. Opt. Soc. Am. 1980, 70, 1362-1363. [CrossRef]

5. El-Bashir, S.M. Enhanced fluorescence polarization of fluorescent polycarbonate/zirconia nanocomposites for second generation luminescent solar concentrators. Renew. Energy 2018, 115, 269-275. [CrossRef]

6. Rowan, B.C.; Wilson, L.R.; Richards, B.S. Advanced material concepts for luminescent solar concentrators. IEEE J. Sel. Top. Quantum Electron. 2008, 14, 1312-1322. [CrossRef]

7. Slooff, L.H.; Bende, E.E.; Burgers, A.R.; Budel, T.; Pravettoni, M.; Kenny, R.P.; Dunlop, E.D.; Büchtemann, A. A luminescent solar concentrator with 7.1\% power conversion efficiency. Phys. Status Solidi Rapid Res. Lett. 2008, 2, 257-259. [CrossRef]

8. Van Sark, W.G.J.H.M.; Krumer, Z.; De Mello Donegá, C.; Schropp, R.E.I. Luminescent solar concentrators: The route to $10 \%$ efficiency. In Proceedings of the 2014 IEEE 40th Photovoltaic Specialist Conference, Denver, CO, USA, 8-13 June 2014.

9. Rafiee, M.; Chandra, S.; Ahmed, H.; McCormack, S.J. An overview of various configurations of luminescent solar concentrators for photovoltaic applications. Opt. Mater. 2019, 91, 212-227. [CrossRef] 
10. Liang, T.S.; Pravettoni, M.; Deline, C.; Stein, J.S.; Kopecek, R.; Singh, J.P.; Luo, W.; Wang, Y.; Aberle, A.G.; Khoo, Y.S. A review of crystalline silicon bifacial photovoltaic performance characterisation and simulation. Energy Environ. Sci. 2019, 12, 116-148. [CrossRef]

11. Valdivia, C.E.; Li, C.T.; Russell, A.; Haysom, J.E.; Li, R.; Lekx, D.; Sepeher, M.M.; Henes, D.; Hinzer, K.; Schriemer, H.P. Bifacial photovoltaic module energy yield calculation and analysis. In Proceedings of the IEEE 44th Photovoltaic Specialist Conference, Washington, DC, USA, 25-30 June 2018.

12. Soria, B.; Gerritsen, E.; Lefillastre, P.; Broquin, J.E. A study of the annual performance of bifacial photovoltaic modules in the case of vertical facade integration. Energy Sci. Eng. 2016, 4, 52-68. [CrossRef]

13. Vishwanathan, B.; Reinders, A.H.M.E.; de Boer, D.K.G.; Desmet, L.; Ras, A.J.M.; Zahn, F.H.; Debije, M.G. A comparison of performance of flat and bent photovoltaic luminescent solar concentrators. Sol. Energy 2015, 112, 120-127. [CrossRef]

14. Reinders, A.H.M.E.; De La Gree, G.D.; Papadopoulos, A.; Rosemann, A.; Debije, M.G.; Cox, M.; Krumer, Z Leaf roof designing luminescent solar concentrating PV roof tiles. In Proceedings of the 2016 IEEE 43rd Photovoltaic Specialists Conference (PVSC), Portland, OR, USA, 5-10 June 2016; pp. 1-5.

15. Klampaftis, E.; Ross, D.; Kocher-Oberlehner, G.; Richards, B.S. Integration of color and graphical design for photovoltaic modules using luminescent materials. IEEE J. Photovoltaics 2015, 5, 584-590. [CrossRef]

16. Prönneke, L.; Gläser, G.C.; Rau, U. Simulations of geometry effects and loss mechanisms affecting the photon collection in photovoltaic fluorescent collectors. EPJ Photovoltaics 2012, 3, 30101. [CrossRef]

17. Wilton, S.R. Monte-Carlo Ray Tracing Simulation for Optimizing Luminescent Solar Concentrators. Master's Thesis, Pennsylvania State University, State College, PA, USA, 2012.

18. Shu, J.; Zhang, X.; Wang, P.; Chen, R.; Zhang, H.; Li, D.; Zhang, P.; Xu, J. Monte-Carlo simulations of optical efficiency in luminescent solar concentrators based on all-inorganic perovskite quantum dots. Phys. $B$ Condens. Matter 2018, 548, 53-57. [CrossRef]

19. Bigg, P.H. The international system of units (SI units). Br. J. Appl. Phys. 1964, 15, 1243-1246. [CrossRef]

20. Wilson, L.R.; Richards, B.S. Measurement method for photoluminescent quantum yields of fluorescent organic dyes in polymethyl methacrylate for luminescent solar concentrators. Appl. Opt. 2009, 48, 212-220. [CrossRef] [PubMed]

(C) 2020 by the authors. Licensee MDPI, Basel, Switzerland. This article is an open access article distributed under the terms and conditions of the Creative Commons Attribution (CC BY) license (http://creativecommons.org/licenses/by/4.0/). 